\title{
Rancang Bangun Sistem Manajemen Pergudangan Berbasis Website Pada PT. Astragraphia (Cabang Depo Jayapura)
}

\author{
Sahnaz Faradiba Taslim ${ }^{* 1}$, llyas Nuryasin ${ }^{2}$, Wildan Suharso ${ }^{3}$ \\ 1,2,3 Teknik Informatika/Universitas Muhammadiyah Malang \\ sahnaz_437048@webmail.umm.ac.id ${ }^{*}$, ilyas@umm.ac.id ${ }^{2}$,wsuharso@umm.ac.id ${ }^{3}$
}

\begin{abstract}
Abstrak
PT. Astragraphia adalah perusahaan yang bergerak pada bidang industri yang dimana aktivitas pengelolaan rantai supplynya harus dijaga dan ditingkatkan, pada bagian pergudangan diperusahaan ini terdapat masalah yaitu dimana belum tersedianya sistem manajemen pergudangan yang bisa diakses di luar lingkungan perusahaan sehingga kurang optimalnya jam kerja karyawan karena harus kembali ke kantor untuk melakukan pengecekan stok barang ataupun memberikan validasi barang yang berupa invoice. Pada saat ini PT. Astragraphia telah memiliki aplikasi namun hak akses aplikasi tersebut terbatas hanya dilingkungan perusahaan sehingga menyulitkan karyawan jika berada diluar perusahaan. Dengan ini menjadikan tidak efektifnya jam kerja karyawan jika ingin mengecek barang, mengorder barang ke pusat dan juga menyerahkan bukti pembelian barang yang berupa invoice kepada pelanggan. Berdasarkan pemasalahan diatas penelitian ini bertujuan untuk membangun sebuah sistem manajemen pergudangan berbasis website dengan menggunakan framework Codelgniter dan metodologi yang digunakan SDLC (System Development Life Cycle) model Waterfall guna untuk memaksimalkan kegiatan pengolahan data barang pada gudang cabang depo Jayapura. Hasil dari penelitian ini adalah Rancang bangun sistem manajemen pergudangan yang akan membantu kegiatan pengolah data barang yang masuk dan keluar, penyuplai, transaksi pelanggan dan pembuatan laporan barang.
\end{abstract}

Kata Kunci: Sistem Manajemen, Pergudangan, Waterfall, Website

\begin{abstract}
PT. Astragraphia is a company engaged in the industrial sector where its supply chain management activities must be maintained and improved, in the warehousing section of this company there is a problem where there is no available warehousing management system that can be accessed outside the company environment so employees work hours are not optimal because they have to return to office to check the stock of goods or provide validation of goods in the form of invoices. At this time PT. Astragraphia already has an application but the access rights of the application are limited only to the company environment making it difficult for employees if they are outside the company. This makes it ineffective in working hours for employees if they want to check goods, order goods to the center and also submit proof of purchase of goods in the form of invoices to customers. Based on the above problems, this study aims to build a website-based warehousing management system using the Codelgniter framework and the methodology used in the Waterfall Model Development Life Cycle (System Development Life Cycle) to maximize the data processing activities of goods at the Jayapura depot branch warehouse. The results of this study are the warehousing management system design that will assist data processing activities for incoming and outgoing goods, suppliers, customer transactions and reporting of goods.
\end{abstract}

Keywords: Management System, Warehouse, Waterfall, Website

\section{Pendahuluan}

Pada era globalisasi sekarang ini teknologi informasi pengggunaanya semakin lama semakin meningkat, begitu juga dengan penggunaan internet yang semakin banyak perusahaan memerlukan untuk keperluan menjalankan aktivitas perusahaan tersebut. Dengan internet pengaksesan informasi dapat berlangsung dengan cepat, efisien dan akurat. Semakin mudah pengaksesan informasi dari perusahaan maka semakin mudah perusahaan tersebut berkembang menjadi lebih baik. 
Perseroan terbatas (PT) adalah sebuah badan usaha yang besar modal perseroan tersebut tercantum dalam anggaran dasar. Kekayaan perusahaan terpisah dari kekayaan pribadi sehingga perusahaan memiliki harta kekayaan sendiri [1]. Astragraphia merintis perjalanan bisnis dimulai dari tahun 1971 sebagai Divisi Xerox di PT Astra Internasional yang kemudian pada tahun 1975 terpisahkan menjadi badan hukum yang berdiri sendiri. Pada tangga 22 April 1976 Astragraphia dipilih secara langsung menjadi distributor eksklusif dari Fuji Xerox Co. Ltd. Jepang di seluruh Indonesia dengan cakupan usaha sebagai penyedia alat perkantoran dan pelayanan purna jualnya. Astrgraphia sendiri mempunyai 5 cabang jaringan distributor di seluruh Indonesia dan 90 depo diseluruh pelosok Indonesia. [2].

Perusahaan yang bergerak dibidang industri ini harus dengan baik mengelolah rantai suplainya. Karena dengan tidak tepatnya mengelolah kesediaan barang pada gudang akan berakibat pada sistem penjualannya, sedangkan kelebihan stok akan berakibat penumpukan barang dan berpengaruh pada meningkatnya biaya. Selain itu kordinasi antar gudang sanagt diperlukan sebagai salah satu mata rantai suplai yang utama. Dimana kantor pusat perusahaan dapat berbagi informasi dan mengumpulkan informasi mengenai masing-masing gudang agar pengelolaan barang dan pernecanaan penjualan barang dapat dilakukan dengan baik.

Saat ini PT. Astragraphia telah memiliki aplikasi sistem manajemen pergudangan hanya saja aplikasi tersebut memiliki akses terbatas yaitu dilingkungan perusahaan saja sehingga menyulitkan para karyawan yang ingin mengakses aplikasi tersebut diluar kantor untuk melihat stok barang digudang ataupun memberi bukti berupa invoice untuk pelanggan jika telah menerima barang yang dibeli tersebut. Dengan banyaknya barang yang harus di kelolah oleh karyawan bagian pergudangan berkaitan dengan keluar-masuknya barang, pengurangan barang yang rusak mapun hilang maka diperlukan sistem kontrol barang yang bersifat "online" sehingga memudahkan karyawan dalam melihat jumlah barang tersisa, tambahan barang yang masuk, pemberian invoice pada pelanggan agar bisa di ketahui secara cepat, tepat dan akurat.

Berdasarkan permasalahan tersebut maka pada penelitian ini akan dibuat sebuah Sistem Manajemen pergudangan berbasis website untuk menyelesaikan masalah menggunakan model metode Waterfall. Penggunaan model metode ini dipilih karena merupakan salah satu model pengembangan perangkat lunak yang ada di dalam model SDLC (Squence Development Life Cycle). SDLC (Squence Development Life Cycle) sering disebut juga proses mengubah sesuatu sistem perangkat lunak dengan menggunakan model-model dan metodologi yang digunakan orang untuk mengembangkan sistem [3].

Sistem Manajemen Pergudangan Berbasis Website memudahkan karyawan dalam pengolahan dan menyimpan data. Pengelolaan data disimpan kedalam database MySQL serta dapat diakses melalui komputer dan perangkat lainnya yang tersambung ke jaringan internet. Sistem manajemen pergudangan ini dibuat berbasis website agar dapat diakses oleh karyawan untuk melihat stok barang ataupun invoice kepelanggan.

Dengan pengembangan sistem manajemen pergudangan ini, diharapkan akan dapat menyelesaikan permasalahan yang dihadapi karena pada dasarnya pengolahan data yang baik akan menghasilkan informasi yang akurat, efektif, efisien sehingga dapat dijadikan sebagai dasar dalam pengambilan keputusan serta memberikan keunggulan kompetitif dan dapat memenuhi target kinerja perusahaan [4].

\section{Metode Penelitian}

\subsection{Model Pengembangan Sistem}

Pada tahap penyelesaian pembuatan tugas akhir ini menggunakan beberapa tahapan, diantaranya seperti pada Gambar 1.

\subsubsection{Studi Literatur}

Pada pengembangan sistem manajemen pergudangan berbasis website ini dilakukan rancangan sistem menggunakan metodeologi SDLC (System Develompment Life Cycle) dengan model Waterfall memungkinkan adanya perubahan sistem pada tahap tertentu tanpa harus menyelesaikan seluruh tahapan pengembangan sistem [5]. Adapun tahap pengembangan waterfall diantaranya digambarkan pada Gambar 2.

Pada Gambar 2 digambarkan tahapan pengembangan yang digunakan pada sistem. Mulai dari tahap analysis, design, code dan test. 
1. Analysis

Dalam tahap ini dilakukan penganalisaan apa saja kebutuhan dari sistem mulai dari kebutuhan fungsional maupun non fungsional.

2. Design

Tahap desain merupakan tahapan selanjutnya dari tahap analisis dimana tahap ini dilakukan desain sistem dari website seperti interface dan desai database yang akan diterapkan kedalam sistem manajemen pergudangan.

3. Code

Pada tahap ini penerapan desain database serta desain interface kedalam bahasa pemrograman dimana bahasa yang dipakai adalah menggunakan bahasa PHP untuk website [5].

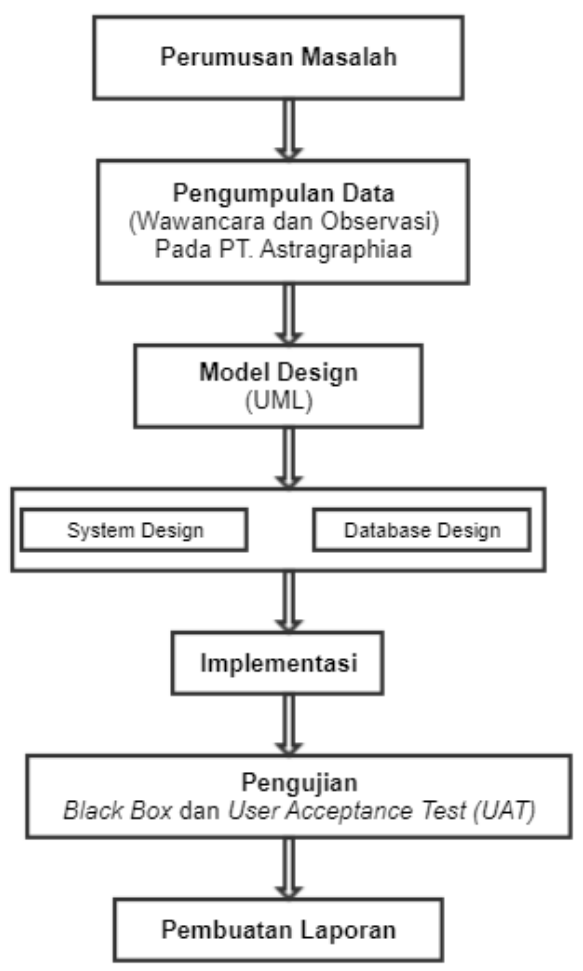

Gambar 1. Tahapan Pengembangan Sistem

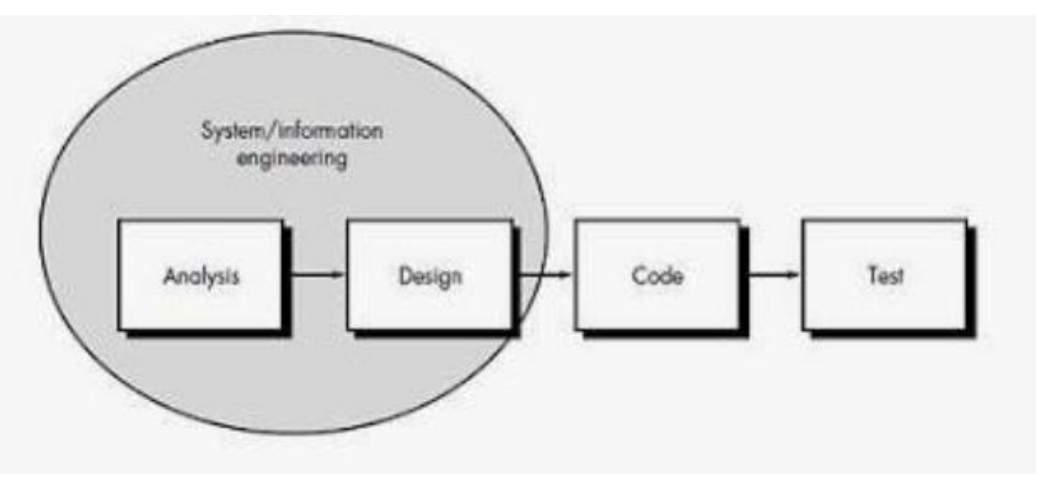

Gambar 2. Model Waterfall

\subsection{Analisa Kebutuhan}

Analisis kebutuhan merupakan langkah awal untuk menentukan gambaran perangkat yang akan dihasilkan ketika developer akan melakukan pembuatan software. Software yang baik dan sesuai dengan kebutuhan pengguna sangat tergantung pada keberhasilan dalam melakukan analisa kebutuhan. 


\subsubsection{Kebutuhan Pengguna}

Kebutuhan pengguna menggambarkan fungsi dan fitur sistem dari prespektif pengguna. Pengembangan Sistem Manajemen Pergudangan berfokus pada 3 pengguna yang dimana setiap pengguna akan saling terhubung dengan pengguna yang lain. Sistem Manajemen Pergudangan ini dibagi menjadi 3 pengguna yaitu Administrator, Karyawan dan Pelanggan. Setiap pengguna dapat melakukan tugasnya sesuai kebutuhan pengguna yang telah di deksripsikan. Peran tertinggi adalah Karyawan sebagai Pengelola pesana dari pelanggan, kemudian Admin sebagai Administrartor dan pelanggan sebagai yang melakukan pemesanan dan konfirmasi barang yang telah diterima.

\subsection{Desain Sistem}

Pada pengembangan Sistem Manajemen Pergudangan Berbasis Website ini terdapat 3 aktor sebagai penggunanya. 3 aktor tersebut diantaranya Admin yang menjadi Administrator, Karyawan sebagai pengelolah tagihan dan pesanan dan Customer sebagai penerima tagihan.

\subsubsection{Arsitektur Sistem}

Pada pengembangan Sistem Manajemen Pergudangan Berbasis Website ini berdasarkan apa yang telah dijelaskan pada Kebutuhan Fungsional dan merupakan gabungan dari software, hardware dan user. Gambar 3 berikut ini adalah gambaran arsitektur dai implementasi pengembangan sistem yang akan diterapkan.

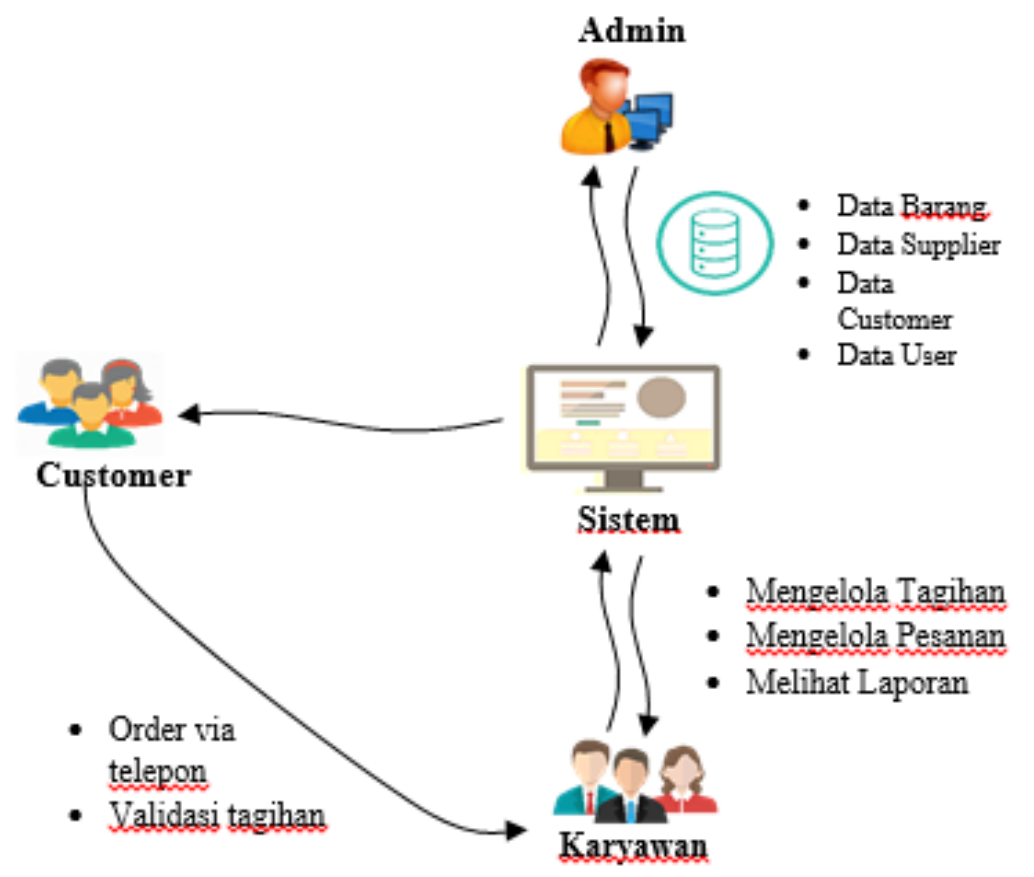

Gambar 3. Arsitektur Sistem Manajemen Pergudangan Berbasis Website

Pada pengembangan Sistem Manajemen Pergudangan ini terdapat 3 aktor. 3 aktor tersebut adalah Admin sebagai Administator, Karyawan sebagai yang mengelolah data pesanan dan data tagihan, Customer yang juga sebagai penerima invoice tagihan barang yang dimana akses sistem tetap dilakukan oleh karyawan.

\section{Implementasi}

\subsection{Implementasi Sistem}

Implementasi sistem dilakukan berdasarkan analisis keseluruhan kebutuhan yang dibutuhkan oleh sistem. Sistem ini merupakan website berbasis online yang dibuat menggunakan bahasa pemrograman PHP dan database yang digunakan MySQL dengan Framework Codelgniter, sehingga akan memudahkan user dalam penggunaannya. Pada tahap implementasi ini user dibagi menjadi 2 akses yaitu akses admin dan akses karyawan. 
1. Login (admin dan karyawan)

Pada halaman login ini user akan menginputkan username dan password.

\section{Dashboard (admin)}

Pada halaman ini tampilan Dashboard yang isinya terdiri diagram, grafik dan beberapa menu diantaranya master data customer,master data supplier, master data item, report item in dan report item-out

\section{Master Data (admin dan karyawan )}

Pada halaman master data admin terdapat 3 sub menu yaitu master data item, master data supplier dan master data customer.

\subsection{Master data Customer (admin dan karyawan)}

Pada halaman ini admin dapat menginputkan data customer baru, mengedit data customer, melihat transaksi terakhir dan menghapus data.

\subsection{Master data Supplier (admin dan karyawan)}

Pada halaman ini admin dapat menginputkan data supplier baru, mengedit data supplier dan menghapus data supplier

\subsection{Master data Item (admin dan karyawan)}

Pada halaman ini admin dapat menginputkan data item baru, mengedit data item, melihat biodata supplier dan menghapus data item.

\subsection{Report item-In (admin dan karyawan)}

Pada halaman ini admin memilih tanggal awal dan akhir untuk mencetak laporan item yang masuk, ada button view dan print PDF. Yang dimana kalo button view di klik akan tampil tabel sesuai tanngal yang diinputkan dan jika button print PDF di klik akan tampil laporan dalam bentuk format PDF.

\section{Report item-out (admin dan karyawan)}

Pada halaman ini admin memilih tanggal awal dan akhir untuk mencetak laporan item yang keluar, ada button view dan print PDF. Yang dimana kalo button view di klik akan tampil tabel sesuai tanngal yang diinputkan dan jika button print PDF di klik akan tampil laporan dalam bentuk format PDF.

\section{Supply in (karyawan)}

Pada Halaman ini hanya bisa diakses oleh karyawan. Pada halaman ini karyawan dapat melakukan input data barang dan menghapus data barang.

\section{Supply Out (karyawan)}

Pada halaman ini karyawan dapat melakukan transaksi pembelian barang, mencetak invoice, mengedit data dan menghapus data.

\section{Log out (admin dan karyawan)}

Pada halaman ini user dapat keluar dari sistem dengan memilih button seblah kanan atas kemudian pilih button log out.

\subsection{Pengujian}

Pengujian sistem merupakan salah satu langkah dalam perancangan sebuah sistem berbasis website dengan tujuan menemukan kelebihan dan kekurangan dari fungsi-fungsi yang ada pada sistem. Pengujian yang akan dilakukan pada sistem ini yaitu pengujian Black Box, berikut dijelaskan fungsional pada Tabel 1 dan Tabel 2 dibawah ini.

Tabel 1. Pegujian Black box (Admin)

\begin{tabular}{clc}
\hline $\begin{array}{c}\text { Deskripsi } \\
\text { Pengujian }\end{array}$ & \multicolumn{1}{c}{ Prosedur Pengujian } & Keterangan \\
\hline \multirow{5}{*}{ Login } & $\begin{array}{l}\text { Masukkan user name dan } \\
\text { password }\end{array}$ & $\checkmark$ \\
\cline { 2 - 3 } & $\begin{array}{l}\text { Salah username atau } \\
\text { password tampil pesan } \\
\text { "uncorrect password" }\end{array}$ & $\checkmark$ \\
\cline { 2 - 3 } & $\begin{array}{l}\text { Masuk kehalaman } \\
\text { dashboard admin }\end{array}$ & $\checkmark$ \\
\hline Dashboard & $\begin{array}{l}\text { Tampil diagram dan grafik } \\
\text { top item dan top customer }\end{array}$ & $\checkmark$ \\
\hline & Create item baru & $\checkmark$ \\
\hline
\end{tabular}




\begin{tabular}{|c|c|c|}
\hline \multirow{4}{*}{$\begin{array}{l}\text { Master Data } \\
\text { Item }\end{array}$} & $\begin{array}{l}\text { Jika tidak menginputkan } \\
\text { salah satu data akan } \\
\text { muncul pesan "harap isi } \\
\text { bidang ini" }\end{array}$ & $\checkmark$ \\
\hline & View biodata supplier & $\checkmark$ \\
\hline & Edit dat item & $\checkmark$ \\
\hline & Delete data item & $\checkmark$ \\
\hline \multirow{4}{*}{$\begin{array}{l}\text { Master data } \\
\text { Supplier }\end{array}$} & Create Supplier baru & $\checkmark$ \\
\hline & $\begin{array}{l}\text { Jika tidak menginputkan } \\
\text { salah satu data akan } \\
\text { muncul pesan "harap isi } \\
\text { bidang ini" }\end{array}$ & $\checkmark$ \\
\hline & Edit data Supplier & $\checkmark$ \\
\hline & Delete Data Supllier & $\checkmark$ \\
\hline \multirow{5}{*}{$\begin{array}{l}\text { Master data } \\
\text { Customer }\end{array}$} & Create Customer baru & $\checkmark$ \\
\hline & $\begin{array}{l}\text { Jika tidak menginputkan } \\
\text { salah satu data akan } \\
\text { muncul pesan "harap isi } \\
\text { bidang ini" }\end{array}$ & $\checkmark$ \\
\hline & View history transaction & $\checkmark$ \\
\hline & Edit data customer & $\checkmark$ \\
\hline & Delete data Customer & $\checkmark$ \\
\hline \multirow{3}{*}{$\begin{array}{l}\text { Report (item } \\
\text { in) }\end{array}$} & $\begin{array}{l}\text { Pilih tanggal awal dan akhir } \\
\text { untuk di cetaknya laporan }\end{array}$ & $\checkmark$ \\
\hline & $\begin{array}{l}\text { view menampilkan tabel } \\
\text { laporan sesuai dengan } \\
\text { tanggal awal dan akhir yang } \\
\text { dipilih }\end{array}$ & $\checkmark$ \\
\hline & $\begin{array}{l}\text { Button print PDF } \\
\text { menampilkan laporan dalam } \\
\text { bentul PDF }\end{array}$ & $\checkmark$ \\
\hline \multirow{3}{*}{$\begin{array}{l}\text { Report (item } \\
\text { out) }\end{array}$} & $\begin{array}{l}\text { Pilih tanggal awal dan akhir } \\
\text { untuk di cetaknya laporan }\end{array}$ & $\checkmark$ \\
\hline & $\begin{array}{l}\text { view menampilkan tabel } \\
\text { laporan sesuai dengan } \\
\text { tanggal awal dan akhir yang } \\
\text { dipilih }\end{array}$ & $\checkmark$ \\
\hline & $\begin{array}{l}\text { Button print PDF } \\
\text { menampilkan laporan dalam } \\
\text { bentul PDF }\end{array}$ & $\checkmark$ \\
\hline \multirow[t]{2}{*}{ Log out } & $\begin{array}{l}\text { Klik button admin ada } \\
\text { pilihan log out }\end{array}$ & $\checkmark$ \\
\hline & Tampil halaman login & $\sqrt{ }$ \\
\hline
\end{tabular}

Tabel 2. Pengujian Black Box (Karyawan)

\begin{tabular}{clc}
\hline $\begin{array}{c}\text { Deskripsi } \\
\text { Pengujian }\end{array}$ & \multicolumn{1}{c}{ Prosedur Pengujian } & Keterangan \\
\hline \multirow{2}{*}{ Login } & $\begin{array}{l}\text { Masukkan user name dan } \\
\text { password }\end{array}$ & $\checkmark$ \\
& $\begin{array}{l}\text { Salah username atau } \\
\text { password tampil pesan } \\
\text { "uncorrect password" }\end{array}$ & $\checkmark$ \\
& $\begin{array}{l}\text { Masuk kehalaman } \\
\text { dashboard admin }\end{array}$ & $\checkmark$ \\
\hline Dashboard & $\begin{array}{l}\text { Tampil diagram dan grafik } \\
\text { top item dan top customer }\end{array}$ & $\checkmark$ \\
\hline & Create item baru & $\checkmark$ \\
\hline
\end{tabular}

REPOSITOR, Vol. 2, No. 6, Juni 2020: 737-744 


\begin{tabular}{|c|c|c|}
\hline \multirow{4}{*}{$\begin{array}{l}\text { Master Data } \\
\text { Item }\end{array}$} & $\begin{array}{l}\text { Jika tidak menginputkan } \\
\text { salah satu data akan } \\
\text { muncul pesan "harap isi } \\
\text { bidang ini" }\end{array}$ & $\checkmark$ \\
\hline & View biodata supplier & $\checkmark$ \\
\hline & Edit dat item & $\checkmark$ \\
\hline & Delete data item & $\checkmark$ \\
\hline \multirow{4}{*}{$\begin{array}{l}\text { Master data } \\
\text { Supplier }\end{array}$} & Create Supplier baru & $\checkmark$ \\
\hline & $\begin{array}{l}\text { Jika tidak menginputkan } \\
\text { salah satu data akan } \\
\text { muncul pesan "harap isi } \\
\text { bidang ini" }\end{array}$ & $\checkmark$ \\
\hline & Edit data Supplier & $\checkmark$ \\
\hline & Delete Data Supllier & $\checkmark$ \\
\hline \multirow{5}{*}{$\begin{array}{l}\text { Master data } \\
\text { Customer }\end{array}$} & Create Customer baru & $\checkmark$ \\
\hline & $\begin{array}{l}\text { Jika tidak menginputkan } \\
\text { salah satu data akan } \\
\text { muncul pesan "harap isi } \\
\text { bidang ini" }\end{array}$ & $\checkmark$ \\
\hline & View history transaction & $\checkmark$ \\
\hline & Edit data customer & $\checkmark$ \\
\hline & Delete data Customer & $\checkmark$ \\
\hline \multirow{4}{*}{ Supply-in } & $\begin{array}{l}\text { Cari barang akan } \\
\text { menampilkan data barang } \\
\text { yang akan diinputkan }\end{array}$ & $\checkmark$ \\
\hline & $\begin{array}{l}\text { Material code dan material } \\
\text { name otomatis terisi jika } \\
\text { memilih pada tabel barang } \\
\text { sebelumnya }\end{array}$ & $\checkmark$ \\
\hline & $\begin{array}{l}\text { Field quantity diinputkan } \\
\text { sendiri }\end{array}$ & $\checkmark$ \\
\hline & Delete data supply in & $\checkmark$ \\
\hline \multirow{6}{*}{ Supply Out } & $\begin{array}{l}\text { Create new payer akan } \\
\text { tampil tabel yang akan diisi }\end{array}$ & $\checkmark$ \\
\hline & $\begin{array}{l}\text { jika salah satu data tidak } \\
\text { diisi akan tampil pesan } \\
\text { "harap isi bidang ini" }\end{array}$ & $\checkmark$ \\
\hline & $\begin{array}{l}\text { Klik button back akan } \\
\text { kembali kehalaman Supply } \\
\text { out }\end{array}$ & $\checkmark$ \\
\hline & Delete data Supply out & $\checkmark$ \\
\hline & Edit data Supply Out & $\checkmark$ \\
\hline & $\begin{array}{l}\text { Invoice akan tercetak dalam } \\
\text { bentuk format PDF }\end{array}$ & $\checkmark$ \\
\hline \multirow{3}{*}{$\begin{array}{l}\text { Report (item } \\
\text { in) }\end{array}$} & $\begin{array}{l}\text { Pilih tanggal awal dan akhir } \\
\text { untuk di cetaknya laporan }\end{array}$ & $\checkmark$ \\
\hline & $\begin{array}{l}\text { view menampilkan tabel } \\
\text { laporan sesuai dengan } \\
\text { tanggal awal dan akhir yang } \\
\text { dipilih }\end{array}$ & $\checkmark$ \\
\hline & $\begin{array}{l}\text { Button print PDF } \\
\text { menampilkan laporan dalam } \\
\text { bentuk PDF }\end{array}$ & $\checkmark$ \\
\hline \multirow{2}{*}{$\begin{array}{l}\text { Report (item } \\
\text { out) }\end{array}$} & $\begin{array}{l}\text { Pilih tanggal awal dan akhir } \\
\text { untuk di cetaknya laporan }\end{array}$ & $\checkmark$ \\
\hline & $\begin{array}{l}\text { view menampilkan tabel } \\
\text { laporan sesuai dengan }\end{array}$ & $\checkmark$ \\
\hline
\end{tabular}




\begin{tabular}{lll}
\hline \multirow{2}{*}{$\begin{array}{l}\text { tanggal awal dan akhir yang } \\
\text { dipilih }\end{array}$} & \\
\cline { 2 - 2 } & $\begin{array}{l}\text { Button print PDF } \\
\text { menampilkan laporan dalam } \\
\text { bentuk PDF }\end{array}$ & $\checkmark$ \\
\hline \multirow{3}{*}{ out } & $\begin{array}{l}\text { Klik button admin ada } \\
\text { pilihan log out }\end{array}$ & $\checkmark$ \\
\hline & Tampil halaman login & $\checkmark$ \\
\hline
\end{tabular}

\section{Kesimpulan}

Berdasarkan pembahasan diatas yang telah dilakukan oleh penulis, dapat disimpulkan beberapa hal untuk sistem Manajemen Pergudangan Berbasis Website pada PT. Astragraphia cabang Depo Jayapura diantara lain:

1. Sistem dirancang dengan menggunakan metode SDLC (System Development Life Cycle) model waterfall. Sistem ini dibangun dan diimplementasikan menggunakan beberapa tahap perancangan yaitu analisa kebutuhan sistem, tahap desain meliputi desain interface dan database. Lalu tahapan selanjutnya menerapkan desain database dan interface kedalam bahasa pemrograman PHP dan terakhir sistem diuji menggunakan teknik blackbox yaitu pengujian fungsionalitas sistem dan pengujian UAT (User Acceptance Test) yaitu teknik pengujian untuk mengetahui apakah sistem yang dikembangkan sudah sesuai yang diharapkan dan keuntungan apa saja yang didapatkan dari sistem berdasarkan sudut pandang end user.

2. Kebutuhan informasi manajemen pergudangan ini meliputi masuk dan keluarnya barang, penyuplai barang, transaksi pembelian dan laporan bulan barang.

3. Sistem yang di rancang menggunakan 2 hak akses yaitu untuk Admin dan Karyawan.

\section{Referensi}

[1] S, A. (2008). Hukum Dalam Ekonomi. Jakarta: Grasindo HIm. 70.

[2] Sekilas Tentang Astragraphia. Astragraphia member of ASTRA. 2018

[3] Sukamto,dan M. Shalahuddin. 2013. Rekayasa Perangkat Lunak Terstruktur Dan Berorientasi Objek. Bandung: Informatika.

[4] Fauziah,S.G, Abdillah,G, Renaldi,F.(2015) Perancangan dan Implementasi Sistem Pada PT.Feedmill Indonesia. Perancangan dan Implementasi Warehouse...

[5] Taqwa Maulana, Rizki. 2015. Pengembangan Sistem Informasi Manajemen Inventory Bengkel dan Laboratorium Dengan Program Delphi Di SMK Muhammadiyah Prambanan, Yogyakarta. 